and in front of the vertebral column, but though uncovered by ribs it is well protected by the surrounding structures; behind the gland rests on fluid cushions formed by the aorta, vena cava, and numerous Iymphatic vessels ; around it is the duodenum, which, when distended, projects beyond it ; in front is the lowest part of the stomach, rarely entirely free from food; while still further in front the lower part of the right lobe of the liver partly covers it, and last, but not least, are the thick recti muscles. I will consider for a minute the effect of a blow from a broad object, such as the buffer of a locomotive, as in Mr. Brown's case. If the blow were direct, resistance would be offered by the lower portion of the chest, and the ribs would probably have to give way before the spinal column could be reached. Were it possible for the ribs to bend sufficiently the liver would be doubled up by such a blow, and would be far more likely to suffer than the pancreas. If the body were inclined backwards, and the blow consequently obliquely urwards, a lower lumbar vertebra would be struck before the pancreas could be injured. But while the head of the pancreas is most exposed, it is with the tail of the gland that cysts are generally connected, and it would be an impossibility to injure that portion of the pancreas by means of an object like the buffer of a locomotive. Not only is the tail of the pancreas to the left of the costal margin, but it turns backwards from the head, so that the spinal column would be struck before the gland could be squeezed against the kidney and its bloodvessels. In connexion with the second point, I may refer to one case, which is interesting as regards the discussion of the effect of a buffer accident. In that case a squeeze between two railway waggons was followed at the end of a year by the appearance of a cyst that contained chocolate-coloured fluid, obviously blood. ${ }^{3}$ Here a cyst, supposed to be con. nected with the pancreas, although sanguineous, did not appear until a year after the injary. The third point mentioned was that sanguineous cysts which are unconnected with the pancreas may follow at an interval after an injury. ${ }^{4}$ In one case sich a cyst developed in front of the right kidney, in another in the small omentum. Two years had elapsed between the appearance of the cyst and the injury in the former, and six months in the latter. The reader will naturally ask, if pancreatic cysts are not directly due to injury of the gland, in what way does that injury act, it being allowed that the connexion with injury is indisputable? I have suggested through the nervous system. ${ }^{5}$ This may seem unreasonably hypothetical, but the following are a few points in favour of it : firstly, the symmetry of hæmorrhages that occasionally destroy the supra-renal capsules suggests that a central cause is responsible for those bæmorrhages; secondly, hæmorrhage into the pancreas is frequently accompanied by spots of fat necrosis over the peritoneum, which it is most reasonatle to conclude are trophic in nature, as suggested by Dr. Rolleston; thirdly, a peripheral injury may give rise to a central nervous lesion, as is sometimes the case in paralysis agitans and progressive muscular atrophy. Fourthly, the taking of one's wind by a blow in " the pit of the stomach" reveals a peculiar sensitiveness of the nervous system connected with the epigastrium to peripheral impressions. In connexion with the second point I may briefly refer to a case brought before the Pathological Society of London, on Oct 18th, 1892, by Dr. Rolleston. A man who bad been knocked down by a cart, which passed over his abdomen, suffered from repeat $\mathrm{d}$ attacks of abdo. minal pain. A year and a half after the accident he was seized with severe abdominal pain and romiting. He was supposed to be suffering from intestinal obstruction and laparotomy was performed. At the post-mortem examination hæmorrhage was found around the pancreas, and numerous spots of fat necrosis over the peritoneum. Dr. Rolleston thought that the hæmorrhage around the pancreas caused disturbance of the sympathetic system, which led to trophic changes in the peritoneum, but it seems more probable that the original injury gave rise to a nerve lesion, which manifested its presence by abdominal pain, and finally led to bæmorrhage in the neighbourhood of the pancreas and to fat necrosis. I regard pancreatic cysts merely as manifestations of hæmorrhage around the pancreas, which may arise in the gland itself or in its neighbourhood and affect the gland secondarily by pressure. The main seat of the hæmorrbage appears to be usually the transverse mesocolon. The history of many cases is

3 Steele : Chicago Medical Journal, April, 1885.

4 Vide Bulletin de la Socié'é Anatomique, 1885, p. 29 , and L'Union Modicale, 1877, vol. xliv., p. 82.

suy's Hospital Reports, 1892. precisely the same as the case just mentioned. There is an injury, followed by a period of abdominal pain, and finally the sudden appearance of a cyst which is found to contain blood. Although I have thus suggested that the effect of injury in the production of pancreatic cysts is indirect, I should not like to extend that view to the peritonitis that has accompanied the cysts in the two cases to which I have specially referred. Probably the association was a mere coincidence. Some lesion of the peritoneum may have led to the escape of a small quantity of blood not sufficient in amount to set up more acute peritonitis. An interesting case of subacute peritonitis following injury is recorded by Mr. Edmund Owen. ${ }^{6}$

Clifton, Bristol.

\section{"ANOREXIA NERVOSA."}

Bx W. J. COLLINS, M.D., M.S., B.Sc, D.P.H. LoND., FELLOW OF THE UNIVERSITY OF LONDON.

THE last contribution to medical literature made by Sir William Gull was a brief note under the above title. ${ }^{1}$ It was the case of a girl fourteen years of age who exhibited a morbid aversion to food and who was reduced to a skeleton, but after six weeks' rational nursing and treatment she was restored to bealth and plumpness. A case strikingly similar to this has recently been under my care.

A girl seven and a half years old, of healthy ancestry, had for ten weeks prior to her admission to tbe London Temperance Hospital persistently refused food and had only partaken of very small quantities after much coaxing. She had attended for some time at a children's hospital for nervous debility but latterly had remained at home, lying doubled up in bed, an object of compassion to her friends and neighbours who anticipated ber early demise. On admission to huspital in September, 1893, her skin was dirty and she was infested with pediculi ; the emaciation was extreme. The legs and thighs were rigidly flexfd, and any manipulation evoked tenderness and tears. The joints, however, were unaffected and the reflexes were normal. Her weight was 2 st. $5 \mathrm{lb}$. The circumference of the chest was $20 \frac{3}{4} \mathrm{in}$., and of the abdomen $18 \frac{1}{2}$ in. at the umbilical level ; the upper arm measured a little over 4 in. around, and the legs 5 辛in All the organs and excretions were normal, but some defined swelling and tenderness were noticeable over the outer part of the left thigh. More remarkable, however, were the mental phenomena, which I requested the sister of the ward to specially observe and to notify to me. The child was reported to be very deceitful and intensely selfish; she took no notice of the other children in the ward, was self-absorbed, very vain, and "told long stories of other people who had been ill just like her and what terrible things happened to them " She asked for the Bible, as sbe cared for po other book, and she was effusively pious in conversation, though she used foul language to the nurses and was filthy in her habits. At first it was difficult to feed her, and she concealed her food in the bed; she expressed herself as not wishing to improve-her friends, she said, despaired of her, called her a "poor thing," and could not bear to look at her.

Such is the picture of the perverted ego in this and other cases of the kind, at once the cause of the anorexia and the central feature of this curious ailment-a gloomy selfconcentration, which seems to extract a morbid vanity from the compassion evoked by bodily misery, coupled with a spurious piety. The temperature was generally raised, and later an abscess was opened in the left thigh; the wound healed rapidly. Massage with neat's-foot oil, a copious dietary, codliver oil, and some liquor pancreaticus constituted the physical treatment. Her condition immediately began to improve, and with increasing weight and the restored use of her limbs her mental and moral state completely changed. By Nov. 1st she weighed 3st. $2 \mathrm{lb}$., and the sister's last report was that "she played with the other children, seemed interested in everything in the ward, was easily manageable; a very amusing, bright, clever child, always smiling and anxious to be helpful." "The illustrations, from pbotographs taken after an interval of nine weeks, are the best evidence of the change that had taken place.

Besides the case mentioned above, Sir William Gull 
published other cases. ${ }^{2}$ In these, as in some earlier ones referred to in 1868 , the patients were young women or girls, the ages being fifteen, sixteen, seventeen, eighteen, and twenty-three years, though Sir William Gull stated that he had seen the same thing in males. In one fatal case there was nothing morbid discovered post mortem except thrombosis of the femoral veins, cansing cedema of the legs. Laségue ${ }^{3}$ refers to a similar condition of things under the term anorexio hystérique, based upon 8 cases, all females, whose ages ranged from eighteen to thirty-two years. Sir William Gull originally employed the term "apepsia hysterica," but deferred to Laségue, although both agreed that the cause was primarily mental and presumably of cerebral origin. In this case Sir William Gull's nomenclature was less felicitous and prophetic than in the case of myxœdema, whicb he from the first described as "cretinoid." Nandeau 4 relates a case of "une maladie nerveuse accompagnée d'un dé zoût extraordinaire pour les alimens," which is presumably of the

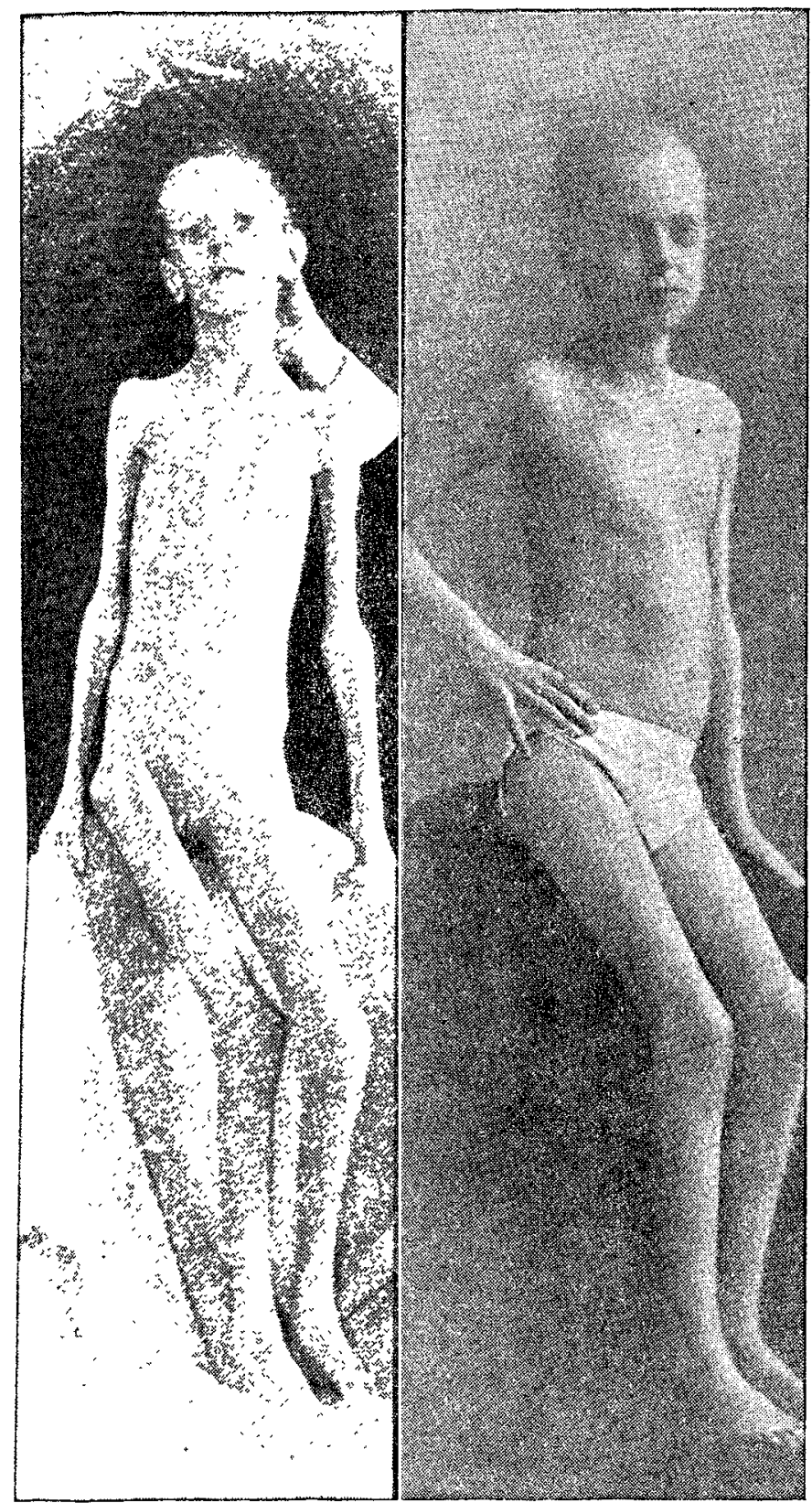

same nature. The "pica" of pregnancy no doubt has some affinity to this condition. Lastly, the case of the Welsh fasting girl and other notorious cases of a quasireligious kind may well have had the morbid mental basis observed in anorexia nervosa; but owing to the relatively recent recognition of moral irsanity the neurotic element escaped attention. The case I now record appears to be that of the youngest patient of the kind on record, she being only seren and a half years old, and it may seem strange to spenk of moroid egotism at such an early age. In this relation. however, I would refer to a case I published some sears ago of feigned monocular blindness in a girl nine years of age. ${ }^{\overline{5}}$ In this case it was proved beyond doubt that the

Transactions of the Clinieal society, vol. vii , 1871

3 Archires Générales de Méde cine. Avril, 1873. * Journal de Médecme, 1789.

5 Rosal London Optthalmic Hospital Reports, vol. xi., part 3. child could see with the eye wbich she obstinately insisted was blind; "her mother repudiated the suggestion of deceit and protested that if her other eye were covered she could not find her way by herself. This done, she did not fall over or encounter any obstacle, but waved her hand feelingly ir front of her and skulked along, keeping a sharp look-out with the "blind' eye on those watching her."

Albert-terrace, Regent's-park, N.W.

\section{CONSIDERATIONS ON GASTRIC ULCER.}

\section{BY J. PORTER PARKINSON, M.D. LOND., F.R.C.S. ENG。}

IN this short paper I propose to deal with some facts and deductions concerning gastric ulcer. As regards its very frequent latency and cure, Grünfeldt in 450 necropsies on persons of both sexes aged from sixty years and upwards found in ninety-two cases the scars of cicatrised ulcers of the stomach. This gives a frequency of one person in five, which frequent occurrence is certainly not diagnosed - for instance, amongst 5000 medical in-patients of University College Hospital I can find only sixty-two cases of gastric ulcer, or about 1.24 per cent. Of course these only represent the severer cases, but of that number only eight died, though the mortality of gastric ulcer is about 4 per cent. of the total mortality. These facts seem to show that ulcer of the stomach is an exceedingly frequent disease, of ten causing no characteristic symptoms, and I believe that many of the intractable cases of dyspepsia that are treated as chronic gastritis really have this lesion as their starting point. In some there is a clear history of hrmatemesis, and the characteristic localised pain in the epigastrium shooting through to the back is present. Such cases are no doubt clear enough, but other cases are more obicure. The slowness of gastric ulcers to cicatrise is a well-knomn fact, but when gastric symptoms have ceased to exist for some years one usually expects a cure to have taken place. But what is the after-history of these patients? I kelieve that the cicatrix may break down from time to time under injudicious irritating diet just as badly healed ulcers of the leg do when irritated; and even without the scar itself breaking down the surrounding gastric epithelium may be more prone than usual to inflame under irritainn Jaworski has described widespread, small-celled infiltratic into the epithelium and inter-glandular tissue of the sub. mucous layen, which lesion would cause a tendency to further inflammation. Rosenheim says that progressive pernicicus anæmia and vomiting and epigastric pain are sequelæ of ulcer of the stomach, but I cannot discover any mention of other sequelæ. I frequently see middle-aged women suffering from gastric irritation, often with severe localised pain in the epigastrium, extending through to the back, in whom there is a distinct history of ulcer. They complain of flatulence, acidity, \&c., coming on an hour or two after food, and always suffer from constipation, but the symptoms are not $\mathrm{moch}$ relieved by purgation alone. The tongue is coated with thin white fur at the centre, the papilla of the tip and edges being enlarged. The expression has that drawn, anxious look so often seen in patients suffering from wlcer.

Mrs. - - forty-seven years of age, seven years ago had all attack of hæmatemesis (losing about two pints of blood) af er having suffered for some months from typical symptoms of gastric ulcer. Under rest and nutrient enemata she recovered and had no stomach symptoms of any importance till January, 1893, when, having been anæmic and out of health for some time, she was seized, after a dietetic indiscreti $n$, with severe pain in the region of the stomach and frequent vomiting; the symptoms speedily subsided and were becoming insignificant when she was again suddenly seized with similar symptoms owing to resuming too soon her ordinary diet. The pain, which was almost constant, was most severe jnst to the left of the ensiform cartilage, but there was a duller pain over the whole of the left hypochondrium. She a] experienced pain in the back. The tongue was thinly coated and the bowels were confined. There was fre quent vomiting, excited even by teaspoonfuls of milk and lime-water, the fluid vomited being almost transparent and containing no free hydrochloric acid, but traces of lactic and butyric acids. There was no bile, but a few sarcinæe and other micrococci were present. She was treated by nutrient enemata, with ice to snck. The bowels having been thoroughly cleared, she was soon able to take D 2 